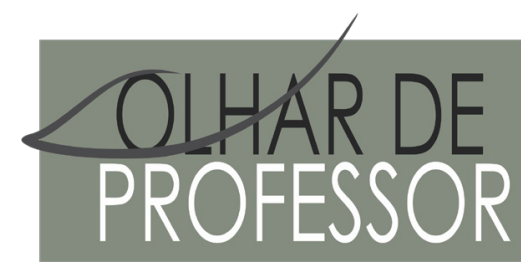

DOl: 10.5212/OLHARPROFR.V.23.2020.15406.209209225047.0514

\title{
DE “A VIDA NÃO PODE PARAR” A “VOCÊ QUE LUTE”: DISCURSOS OFICIAIS, CONTRADISCURSOSE A RESISTENNCIA DE UM CURSINHO POPULAR NA PANDEMIA DA COVID-19
}

\author{
FROM “LIFE CANNOT STOP” TO “YOU THAT FIGHT”: OFFICIAL SPEECHES, COUNTER-DISCOURSES AND \\ THE RESISTANCE OF A POPULAR COURSE IN COVID-19 PANDEMIC
}

\author{
DE “LA VIDA NO PUEDE DETENERSE” HASTA “TÚ QUE LUCHES”: DISCURSOS OFICIALES, \\ CONTRADISCURSOS Y LA RESISTENCIA DE UN CURSO POPULAR EN LA PANDEMIA DEL COVID-19
}

\author{
ALBERTO LOPO MONTALVÃO NETO* \\ FRANCISCO VIEIRA DA SILVA **
}

\begin{abstract}
Resumo: O texto reflete sobre os impactos da pandemia da Covid-19 no contexto brasileiro, por meio de um estudo descritivo-interpretativo, com base na análise discursiva de uma campanha institucional acerca da realização do ENEM no ano de 2020, de uma paródia dessa campanha que circulou no Twitter e da experiência num cursinho popular da cidade de Campinas/SP. As análises mostram que o discurso oficial do atual governo está amparado numa lógica neoliberal, que exclui boa parte dos candidatos do exame, conforme se nota no contradiscurso da paródia e em uma experiência caracterizada por práticas de resistência num cursinho popular.
\end{abstract}

Palavras-chave: ENEM. Discurso. Resistência.

\begin{abstract}
The text reflects about impacts of the Covid-19 pandemic in the Brazilian context, through a descriptiveinterpretative study, based on the discursive analysis of an institutional campaign about the realization of ENEM in 2020, of a parody of this campaign that circulated on Twitter and the experience from a popular course in the city of Campinas/SP. The analysis shows that the official speech of the current government is supported by a neoliberal logic that excludes a good part of the candidates from taking the exam, as it can be seen in the counter-discourse of the parody and in a resistance experience of the popular preparatory course.
\end{abstract}

Keywords: ENEM. Discourse. Resistance.

Resumen: El texto reflexiona sobre los impactos de la pandemia de Covid-19 en el contexto brasileño, a partir de un estudio descriptivo-interpretativo, basado en el análisis de una campaña institucional sobre la realización del ENEM en 2020, de una paródia de esta campaña que ha circulado en Twitter y la experiencia en un curso popular en la ciudad de Campinas/SP. Los análisis muestran que el discurso oficial del gobierno actual está respaldado por una lógica neoliberal que excluye a la mayoría de los candidatos de tomar el examen, como se ha señalado en el contra-discurso de la parodia y en una experiencia caracterizada por prácticas de resistencia en un curso preparatorio popular.

Palabras-clave: ENEM. Discurso. Resistencia.

\footnotetext{
* Mestre em Educação Científica e Tecnológica pela Universidade Federal de Santa Catarina. Doutorando em Educação pela Universidade Estadual de Campinas e Professor do “Cursinho Popular LIBERTE-SE!”. E-mail: montalvaoalberto@gmail.com.

** Doutor em Linguística pela Universidade Federal da Paraíba. Professor efetivo de Linguística e Língua Portuguesa pela Universidade Federal Rural do Semi-Árido (Campus de Caraúbas). Professor Permanente do Programa de Pós-Graduação em Letras pela Universidade do Estado do Rio Grande do Norte e do Programa de Pós-Graduação em Ensino (POSENSINO UERN/IFRN/UFERSA). E-mail: francisco.vieiras@ufersa.edu.br.
} 


\section{INTRODUÇ̄̃O}

No início de maio de 2020, em um momento no qual o Brasil extrapolou a marca de mais dez mil mortes pela Covid-19, doença causada pelo novo coronavírus (Sars-Cov-2), numa pandemia que se alastra pelo mundo, o Ministério da Educação (MEC) lançou uma campanha denominada “A vida não pode parar”, na qual jovens defendiam a realização do Exame Nacional do Ensino Médio (ENEM) no ano em vigor. Somado a isso, deve ser mencionado o fato de que havia uma previsão oficial de que as provas do referido exame seriam efetuadas no formato impresso, nos dias 1 e 8 de novembro e, em formato digital, nos dias 11 e 18 de outubro. Embalados pela fala do ministro da Educação, Abraham Weintraub, para quem o ENEM não foi feito para corrigir injustiças e que, por isso, não haveria motivos para o adiamento do certame, os jovens que enunciavam no vídeo da campanha mostravam-se favoráveis à realização do exame nos moldes previstos e sugeriam que aos candidatos caberia a tarefa de se adequarem às condições impostas.

Buscando compreender discursos que permeiam cenários excludentes e visando refletir acerca de práticas de resistência, problematizaremos, no presente trabalho, os impactos da pandemia no Brasil, por meio de um estudo descritivo-interpretativo realizado através de uma análise discursiva.

\section{CENÁRIO PANDÊMICO NO BRASIL E AS PRÁTICAS DE RESISTÊNCIA}

Vale destacar que, conforme a UNESCO, $80 \%^{1}$ de todos os estudantes do mundo não estão frequentando salas de aulas devido à pandemia. Cerca de 1,3 bilhões encontram-se afastados do cotidiano escolar, em função das medidas de isolamento social, que visam controlar a contaminação pelo novo coronavírus.

Decerto, uma parcela de candidatos ao ENEM não tiveram o ensino totalmente interrompido, se for considerado que: a) as escolas privadas apostaram em estratégias de ensino on-line; b) alguns estados da federação já entraram nessa mesma lógica², tais como Bahia, Ceará, Espírito Santo, Goiás, Mato Grosso do Sul, Pernambuco, Piauí e Rio de Janeiro, que se utilizam de plataformas on-line para a realização de atividades educativas; outros, como Maranhão e Paraná, valeram-se de teleaulas transmitidas na TV aberta; e o estado do Amazonas, o Distrito Federal e o Pará utilizam-se de um modelo misto que incorpora aulas via internet e a TV aberta ${ }^{3}$; c) há regras governamentais que isentam as instituições de ensino de cumprirem o número mínimo exigido de 200 dias letivos anuais pela Medida Provisória n 934, de 2020, ainda que a carga horária não tenha sido reduzida (BRASIL, 2020).

Por outro lado, há de se reconhecer que, de acordo com o Instituto Brasileiro de Geografia e Estatística (IBGE), em 2018, 45,9 milhões de brasileiros não tinham acesso à internet ${ }^{4}$. Ainda de acordo com o levantamento, o celular era o único meio de acesso à internet em 45,5\% dos domicílios. Esse quadro permite problematizar a consecução de um ensino remoto de qualidade, pois, somente com o uso do celular e sob frágeis conexões, dado que o país continua atrasado em relação a outros países na qualidade da internet, fica complicado acompanhar as demandas que esse tipo de avaliação requer. Noutros termos,

\footnotetext{
${ }^{1}$ Disponível em: <<https://noticias.uol.com.br/ultimas-noticias/efe/2020/03/24/unesco-diz-que-80-dos-estudantes-do-mundo-estao-sem-aula-devido-a-covid-19.htm\#: :text=Not\%C3\%ADcias-,Unesco\%20diz\%20que\%2080\%25\%20dos\%20estudantes\%20do\%20mundo\%20est\%C3\%A3o,aula\%20devido\%20\%C3\%A0\%20Covid\%2D19\&text=Paris\%2C\%2024\%20 mar\%20(EFE).\&text=A\%20diretora\%2Dgeral\%20da\%20Unesco,crise\%20causada\%20pela\%20Covid\%2D19.>> Acesso em 30 abr. 2020.

${ }^{2}$ Disponível em: <<https:/g1.globo.com/educacao/noticia/2020/04/09/estados-adotam-plataformas-online-e-aulas-na-tv-aberta-para-levar-conteudo-a-estudantes-em-meio-a-pandemia-de-coronavirus.ghtml >> Acesso em 30 abr. 2020.

${ }^{3}$ De acordo com o relato de um docente de Porto Alegre/RS, numa reportagem do G1, foram entregues, no início da quarentena, alguns materiais físicos, como apostilas. No entanto, nem todos os pais de alunos e/ou responsáveis conseguiram ir buscar na escola esse material de modo que o conteúdo foi disponibilizado numa página do Facebook. Disponível em: <https://g1.globo. com/educacao/noticia/2020/05/21/estudantes-pais-e-professores-narram-apagao-do-ensino-publico-na-pandemia-em-7-estados-e-no-df-atividade-remota-nao-vai-contar-para-o-ano-letivo.ghtml> Acesso em: 22 mai. 2020.

${ }_{4}$ Disponível em: <https://www.convergenciadigital.com.br/cgi/cgilua.exe/sys/start.htm?UserActiveTemplate=site\&infoid=53506\&sid=14> Acesso em: 30 de abril de 2020.
} 
o modo como se estrutura a propaganda do MEC sobre o ENEM entra em contradição com a diversidade de candidatos que pretende prestar o exame, delineando, assim, um cenário de exclusão social.

Não é preciso ir muito longe para constatar o abismo que aparta os que têm docentes à disposição para sanar dúvidas - por meio de programa de estudos previamente elaborados na rede de ensino privado, especialmente em cursinhos preparatórios para o vestibular - dos estudantes que sofrem por realidades adversas - como aqueles pertencentes à zona rural, às comunidades carentes, aos quilombos e às regiões ribeirinhas. Desse modo, a campanha do ENEM torna ainda mais visível essa diferença ao escolher, como protagonistas, jovens - aparentemente oriundos de classes sociais abastadas - que dispõem de um leque de oportunidades e instâncias preparatórias, mesmo diante da impossibilidade de aulas presenciais.

Disso, podemos adiantar que a pandemia descontrói o discurso de que todos seriam afetados da mesma forma. Trata-se, antes, de uma estratégia retórica, empregada para tentar apaziguar o cenário estrutural caracterizado pela falta de equidade social. Na mesma semana em que o Brasil passou dos cem mil afetados pela Covid-19, o presidente da XP Investimentos disse que o país estava indo bem no combate à pandemia, pois o pico nas elites já havia passado. Em contexto similar, o prefeito de Belém/ PA declarou o trabalho doméstico como um serviço essencial. É importante mencionar que, na mesma cidade, os membros da elite com diagnóstico positivo para COVID-19 fazem o uso de UTIs aéreas, em operações que visam à transferência para outros centros, enquanto que a maioria da população morre de insuficiência respiratória, o principal sintoma grave da doença, devido à ausência de unidades de terapia intensiva para todos. Nesse sentido, embora o vírus seja obviamente um agente biológico, o modo como o acesso ao tratamento é distribuído está associado a uma escolha entre os que devem viver e quem pode ser largado à própria sorte. Tal implicação permite-nos respaldar nos estudos acerca do biopoder, mencionados por Foucault (2005), e investigar, portanto, como os mecanismos biológicos entram no regime de saber-poder. Para o filósofo francês, a mecânica que rege a produção da vida, por um lado, estimula a longevidade e a qualidade de vida e, por outro, utiliza-se de mecanismos sutis que fazem com que a morte seja, de algum modo, estimulada.

Nesse clima de extrema dissolução da normalidade sanitária, a campanha do ENEM, cujas inscrições ocorreram de 11 a 22 de maio de 2020, contribui para que seja lançada a cartada que faltava para mostrar mais uma das facetas excludentes orquestradas pelo governo federal. Na peça institucional, um jovem branco, em meio a um cenário que parece ser um quarto de estudos - com muitos livros e um quadro com avisos, organogramas e uma tabela periódica - questiona: "E se uma geração de novos profissionais fosse perdida? Médicos, enfermeiros, engenheiros, professores. Seria o melhor para nosso país?”. A fala emoldura um posicionamento discursivo que busca fomentar um diálogo com a sociedade sobre os impactos negativos devido a um possível impedimento/adiamento do exame, ao apontar que toda uma geração de profissionais seria prejudicada. A ênfase nos profissionais da saúde, como os primeiros a ser enumerados, demonstra o objetivo: focar na qualidade dos serviços de saúde como um aspecto que seria ameaçado com a suspensão do exame.

A seguir, a campanha continua com o jovem recomendando: “A vida não pode parar. É preciso ir à luta, se reinventar, se superar”. Depois aparece outra jovem, também em meio a um cenário de estudos com um laptop e alguns cadernos e lápis - reiterando: "E, por isso, eu quero fazer o ENEM este ano. Para entrar em uma universidade. Estude, de qualquer lugar, de diferentes formas, pelos livros, internet, com a ajuda de professores à distância”. Vale destacar que reverbera, na produção desses discursos, a lógica neoliberal, que focaliza o esforço individual como alternativa possível para o êxito, desconsiderando disparidades sociais e econômicas e a sacralização de princípios inegáveis da liberdade individual de escolha “[...] e da meritocracia, de modo a disseminar ao mesmo tempo, além de uma concorrência agressiva de todos contra todos, inciativas governamentais que funcionam, paradoxalmente, por intermédio de uma individualização" (GADELHA, 2018, p. 243). O apelo feito na campanha do MEC incide por meio do uso de termos evasivos como "invenção" e "superação", principalmente se forem consideradas condições discrepantes, quando não são ofertadas condições mínimas para que os candidatos possam concorrer de maneira equânime no processo haja vista que as desigualdades tendem a se acentuar de maneira voraz no contexto da pandemia. 
A campanha em foco gerou reações na web e uma espécie de paródia foi publicada pelo perfil "Gatilho chicken litte", no Twitter ${ }^{5}$, num vídeo que ganhou repercussão nacional, exibindo, contradiscursivamente, o que está posto na campanha institucional oficial do governo. Na paródia, aqui concebida como um contradiscurso, lemos a seguinte legenda: "Eu percebi que tinha algumas coisinhas erradas com a nova propaganda do ENEM e resolvi fazer a minha própria”. As "coisinhas erradas" de que fala Vic Panuzzo, garota da "nova” propaganda, seriam as estratégias empregadas para suavizar a perversidade do discurso excludente. Numa das passagens do rápido vídeo satírico, por exemplo, ela destaca: "E se a geração morresse por conta de um vírus? E daí? Pais, avós, médicos, professores e advogados... Todos eles iriam para o mesmo lugar. Não seria melhor para nosso país? As mortes não vão parar. É preciso ir à luta, se reinventar". Vemos que, no vídeo em questão, há fragmentos diretos do discurso da campanha institucional do MEC, mesclados com os discursos que minimizam os impactos da Covid-19, como: a) a referência ao emblemático "E daí?”, dito pelo presidente Jair Bolsonaro; b) a banalização da morte expressa na inserção do termo avós e pais entre as categorias das profissões; e c) a constatação de que é preciso se reinventar a despeito das mortes. "Afinal todo mundo tem uma internet como a minha e faz cursinho on-line! Você que lute!”, arremata a garota-propaganda.

Vale destacar que, conforme o posicionamento negacionista de Weintraub, o ENEM é um instrumento meramente avaliativo e destituído de toda a luta de inserção social que o precedeu. A propaganda oficial do governo parece fazer jus a essa concepção, dado o rumo que essas políticas públicas educacionais parecem tomar no país. Para fazer frente a essa pandemia, que não é apenas sanitária, a experiência de um dos autores deste texto, atuante como professor de Biologia, num cursinho popular, mostra-nos como o contato com jovens de estratos sociais pouco privilegiados pode permitir contraposições diante da instauração de nefastos cenários. Estamos, então, no terreno das possibilidades de resistência.

Promovido pelo Coletivo do Movimento de Juventude Enfrente, o Cursinho Popular LIBERTE-SE! atua, desde 2017, com o objetivo de "Lutar por uma educação verdadeiramente LIBERTADORA”. É importante mencionar que o coletivo surgiu a partir de um movimento de militância do Diretório Central dos Estudantes (DCE) da Universidade Estadual de Campinas. Esses estudantes inicialmente fundaram o Coletivo Rompendo Amarras que, posteriormente, originou o Coletivo Domínio Público. Com foco em lutar contra opressões sociais, ao longo dos anos as ações do coletivo difundiram-se para todo o estado de São Paulo. Contudo, devido à transição de governos, em 2016, e em função das novas demandas sociais decorrentes do processo de impeachment ocorrido no período em questão, integrantes do Coletivo Domínio Público criaram o Juventude Enfrente, com a proposta de ir além do contexto universitário. A partir disso, visando romper barreiras sociais, numa concepção de educação libertadora, é criado o LIBERTE-SE.

Composto majoritariamente por professores vinculados aos cursos de graduação e de pós-graduação da UNICAMP, o funcionamento do cursinho ocorre autonomamente, em caráter voluntário. As aulas são realizadas num espaço cedido por uma escola estadual, localizada no centro de Campinas, no estado de São Paulo, e contemplam alunos de várias regiões, priorizando a matrícula de alunos com baixa renda. Todavia, as ações formativas do coletivo não são limitadas ao desejo de ingressar no ensino superior. Há diversos espaços de formação ética, política e social, sendo comum o estímulo ao exercício de práticas relacionadas às discussões que estão para além da sala de aula, tais como a realização de oficinas, idas a eventos culturais, participação em atos políticos e movimentos de arrecadação de recursos para auxiliar os alunos, como, por exemplo, no que se refere ao pagamento de taxas de inscrição de vestibulares.

As atividades presenciais foram paralisadas em 16 de março de 2020, período em que emergiram os primeiros anúncios sobre a suspensão das atividades escolares no estado de São Paulo. A exemplo de demais coletivos, as ações do LIBERTE-SE passaram a ocorrer apenas on-line e foi adotado o Google Classroom como principal ambiente de ensino e de aprendizagem. No entanto, muitas dificuldades foram encontradas nesse contexto: de cerca de duzentos alunos inscritos no início do ano letivo, houve oitenta matriculados. Desse total, atualmente, pouco mais de cinquenta alunos permaneceram vinculados ao cursinho após a paralisação das atividades presenciais. Ademais, observamos que a participação nas aulas representa cerca de, no máximo, 15 alunos em todas as disciplinas que compõem a grade curricular.

\footnotetext{
${ }^{5}$ Disponível em: <https://twitter.com/vicpannunzio/status/1257797384031162368>. Acesso em: 07 maio 2020.

${ }^{6}$ Disponível em: <https://www.facebook.com/pg/libertesecampinas/about/?ref=page_internal>. Acesso em: 13 de agosto de 2020.
} 
Entre os principais motivos para a existência de tal quadro está a dificuldade de acesso dos alunos aos aparelhos eletrônicos e à internet.

É importante ressaltar que, no atual contexto, apesar da sobreposição de matrizes de poder, visivelmente expressas a partir de diversos aspectos que reforçam as desigualdades sociais, num momento em que são colocados em xeque os direitos humanos, a ciência e a própria condição de existência buscamos, de diferentes maneiras, resistir para existir. Além das aulas, mantidas por meio de transmissões on-line e a partir de materiais disponibilizados quinzenalmente, o LIBERTE-SE promove ações contra-hegemônicas. Tal demarcação se dá via manifestações a favor do cancelamento do ENEM, por meio de textos divulgados nas redes sociais ou em outros movimentos, como a live com a hashtag "adiaENEM", que teve a participação de um professor do LIBERTE-SE, um professor do Instituto Federal de Educação, Ciência e Tecnologia de São Paulo (IFSP) e uma aluna do cursinho popular realizar um debate acerca do atual cenário controverso do vestibular. Além disso, é importante salientar que alguns professores do LIBERTE-SE participam de outros coletivos e ações posicionados contrariamente à realização do ENEM.

Em meio às dificuldades do atual cenário brasileiro, marcadas por inúmeras desigualdades, destacam-se as injustiças econômicas, políticas, sociais e ideológicas, as quais tornam evidentes os problemas que afetam os mais pobres e incidem sobre grupos historicamente oprimidos, como negros, mulheres, comunidades indígenas e quilombolas, além de diversos outros que vivenciam a pobreza social das periferias. No contexto atual, pode ser notado um movimento de promoção de um modelo de educação mediada pelas tecnologias digitais, que privilegia a iniciativa privada e endossa, em meio ao caos, oportunidades de lucratividade. Vivenciamos, então, um novo darwinismo social? Uma nova eugenia? São questionamentos que podemos fazer em meio a um cenário social excludente e que se coloca a partir de discursos falaciosos e meritocráticos como “A vida não pode parar”, "é preciso se superar”.

\section{CONSIDERAÇ̃̃ES FINAIS}

Diante do cenário exposto, acreditamos que é necessário resistir. Essa resistência está marcada em cada ação que busque promover a multiplicação de modos educativos que almejem a justiça social. Pensando no âmbito de instâncias como as contracondutas e as atividades de resistência promovidas por coletivos populares, como o LIBERTE-SE, pode-se afirmar que tais ações possibilitam que jovens de classes sociais pouco privilegiadas - que não poderiam arcar com os seus custos na iniciativa privada, principalmente em meio a um cenário marcado por um governo autoritário - possam ter acesso a uma educação de excelência. Vemos que os contradiscursos se materializam de diversas formas, num processo de indignação, o que faz com que manifestações contrárias ao atual governo, outrora denominadas de "balbúrdias", alastrem-se pelas redes sociais. Esses movimentos subversivos, que intencionamos destacar nesta breve reflexão, abrem margens para outras possibilidades que se esvaem das políticas governamentais de desigualdade.

Não se trata da realização do vestibular a todo custo para garantir a "sobrevivência de gerações futuras", nem mesmo que se perca uma "chance" com o seu adiamento, pois oportunidades devem ser oferecidas em condições de equidade. Trata-se, então, de ir contra a uma política excludente e seletiva para que, de fato, a vida não tenha que parar, não em termos de atividades cotidianas, mas no que se refere a um ceifar de vidas por meio dessas ações políticas. Defendemos, assim, que as ações educacionais empregadas nesse momento pandêmico devam seguir dois propósitos: (re) pensar sobre os moldes de educação que vão sendo incorporados na vida comum dos brasileiros e refletir a respeito das próprias estruturas de uma sociedade neoliberalista que, desde muito tempo, já não se sustenta.

\section{REFERÊNCIAS}

BRASIL. Medida Provisória ${ }^{0}$ 934, de $1^{\circ}$ de abril de 2020. Disponível em: http://www.planalto.gov. br/ccivil_03/_ato2019-2022/2020/Mpv/mpv934.htm. Acesso em: 11 de maio de 2020. 
FOUCAULT, M. Em defesa da sociedade. Curso no Collège de France (1975-1976). Trad. Maria Ermantina Galvão. São Paulo: Martins Fontes, 2005.

GADELHA, S. Empresariamento da sociedade e da educação: o complexo corpo-subjetividade do Homo Economicus neoliberal, o imperativo da alta performance e seus efeitos. In: RESENDE, H. (Org.). Michel Foucault: a arte neoliberal de governar a educação. São Paulo: Intermeios, 2018, p. 227-246. 